\title{
Mortality Rate in Covid-19 Positive Patients with Acute Kidney Injury Requiring Hemodialysis
}

\author{
Mehdi Hussain', Zarafshan Zubair ${ }^{2 *}$, Sarah Iftikhar², Elya Tanweer ${ }^{3}$, Baresham Batool ${ }^{4}$ \\ ${ }^{1}$ Consultant Nephrology and Head of dialysis unit, Patel Hospital. \\ ${ }^{2}$ RMO Nephrology Patel Hospital. \\ ${ }^{3} \mathrm{RMO}$ tabba heart hospital. \\ ${ }^{4} \mathrm{RMO}$ peads Mamji Hospital.
}

*Corresponding Author: Zarafshan Zubair, RMO Nephrology Patel Hospital.

Received date: October 04, 2021; Accepted date: December 27, 2021; Published date: January 04, 2022

Citation: M Hussain, Z Zubair, S Iftikhar, E Tanweer, B Batool. (2022). Mortality Rate in Covid-19 Positive Patients with Acute Kidney Injury Requiring Hemodialysis. International Journal of Clinical Case Reports and Reviews. 10(1); DOI: 10.31579/2690-4861/181

Copyright: (C) 2022 Zarafshan Zubair, This is an open access article distributed under the Creative Commons Attributiosn License, which permits unrestricted use, distribution, and reproduction in any medium, provided the original work is properly cited.

\begin{abstract}
Introduction: According to statistics till April, 2020 1,995,983 cases and 131,037 deaths have been reported globally with COVID-19 being a global threat posing great challenges to the healthcare system. Clinical data reviews and researchers have revealed that COVID-19 affects multiple organ especially liver, kidney and heart with primary damage to the respiratory system. Acute kidney injury and COVID-19 infection has been found to be linked to each other but the etiology remains unclear still.

Method: This is an observational retrospective study conducted in nephrology department of Patel Hospital, Karachi. Data was collected retrospectively from medical records of patients. The study was carried out during the time period of March, 2020 till May 2021 for duration of 15 months. Patients with positive COVID-19 PCR and having AKI requiring hemodialysis were included in the study. Data was collected by complete evaluation of COVID-19 patient records and their symptoms, clinical status and final outcome during their hospital stay was noted.
\end{abstract}

Results: The frequency of acute kidney injury requiring hemodialysis in our tertiary care setup was found to be $12.2 \%$ ( $n=41)$. Amongst these there were $53.7 \%$ males $(n=22)$ and $46.3 \%$ females $(n=19)$ and the mean age of patients was found to be $64.82 \pm 11.2$ years. The mean level of lymphocyte count was found to be $11.3+4.8 * 10^{9} / \mathrm{L}$. The in hospital mortality of COVID-19 positive patients having AKI was documented to be $73.2 \%(\mathrm{n}=30)$ as shown in table-4. The other group of patients included 11 patients who recovered from acute kidney injury after hemodialysis sessions and were discharged from the hospital.

Conclusion: Since COVID-19 infection became pandemic in 2020 there still needs to be a lot of research done in different populations. Hospitalized patients with COVID-19 infection should be Screen for kidney impairment and provided proper treatment. There has been found a very close association between the severity of acute kidney injury and mortality among the critically ill patients.

Keywords: mortality rate; acute kidney injury; hemodialysis

\section{Introduction}

COVID-19 is a single stranded RNA virus belonging to corona virdae family of virus and emerged as a pandemic in 2019 starting from city Wuhan, China. It has been named internationally as SARS-COV-2 by researchers and it primarily affects the respiratory system infecting more than 70,000 people during the first five days of pandemic in Wuhan [1]. According to statistics till April, 2020 1,995,983 cases and 131,037 deaths have been reported globally with COVID-19 being a global threat posing great challenges to the healthcare system [2]. Overtime researchers need to be educated about COVID-19 and its presentation. COVID-19 infection of the respiratory tract can be divided into three phases: phase 1 is asymptomatic incubation period, phase 2 symptomatic period and phase 3 being severe acute respiratory syndrome (SARS) with high viral load [3]. COVID-19 affects lung in the form of viral pneumonia, inflammation and endothelial damage causing breathing difficulties [4]. Clinical data reviews and researchers have revealed that COVID-19 affects multiple organ especially liver, kidney and heart with primary damage to the respiratory system. Acute kidney injury and COVID-19 infection has been found to be linked to each other but the etiology remains unclear still [5]. Acute kidney injury is indicated by rising blood urea nitrogen, serum creatinine and uric acid levels from the baseline levels of the patient. In a study conducted in China to analyse risk factors for AKI in COVID-19 positive patients and mortality risk [6]. 
AKI was more prevalent in patients with severe COVID-19 infection and older age groups, although the etiology is unclear. COVID-19 infection severity is found to be increased in older age groups and proportionally the chances for AKI increase [7]. In fewer studies co morbidities are also confounding factors for acute kidney injury such as COVID-19 positive patients having preexisting diabetes mellitus are more susceptible to AKI, whereas this isn't found to be the case with hypertension [8]. Patients having diabetes have raised levels of blood urea nitrogen and serum creatinine as compared to non-diabetes posing more risk to development of AKI. Non modifiable risk factors affecting risk of AKI in COVID-19 positive patients are male gender and older age. Males generally tend to have higher baseline serum creatinine, blood urea nitrogen and uric acid levels in contrast to females. Although we need more studies to analyze the impact of these risk factors on severity of AKI and mortality rate in COVID-19 positive patients. Hence with severe COVID-19 and simultaneous presence of AKI, the mortality rate is found to be proportionally increased in such groups of patients in previous studies. During a retrospective study in China, approximately one third of COVID-19 positive patients with AKI died on the $11^{\text {th }}$ day of admission [9]. AKI and coronavirus relationship to mortality rate was studied previously in the MERS-CoV epidemic which had $43 \%$ mortality rate. Currently patients with co-morbids and severe COVID-19 infection have been found to have $90 \%$ or more mortality rate with the presence of AKI [10].

Our study aims to determine the mortality of COVID-19 positive patients having acute kidney injury requiring hemodialysis during their covid treatment phase.

\section{Method}

\section{Study design}

This is an observational retrospective study conducted in nephrology department of Patel Hospital, Karachi. Data was collected retrospectively from medical records of patients. The study was carried out during the time period of March, 2020 till May 2021 for duration of 15 months.

\section{Study participants}

All patients admitted in the nephrology department of our hospital during the above mentioned time period were reviewed for selection. Patients with positive COVID-19 PCR and having AKI requiring hemodialysis were included in the study. Patients were labelled as COVID-19 positive by PCR testing within the last 72 hours of admission into hospital. Patients with end stage renal disease or having maintenance hemodialysis were excluded from the sample.

\section{Operational definitions}

In our study we defined acute kidney injury (AKI) as increase in serum creatinine level to $\geq 0.3 \mathrm{mg} / \mathrm{dL}$ or increase in baseline serum creatinine levels to $\geq 150 \%$, or initiation of hemodialysis without previous history of chronic kidney disease. Baseline serum creatinine level was taken as serum creatinine at the time of admission at the hospital [11].

\section{Data Source}

Data was collected by complete evaluation of COVID-19 patient records and their symptoms, clinical status and final outcome during their hospital stay was noted. Basic information like age, gender, co-morbidities was extracted from the files. Co-morbidities of patients like hypertension, diabetes mellitus, COPD and ischemic heart disease were noted. Patient's total lymphocyte count, serum creatinine level, CRP, ferritin, D-Dimer and procalcitonin levels were also retrieved from the data. The final outcome of the patients was noted during their clinical course of COVID19 and AKI. All this information was filled on a preformed questionnaire. Patient's identities were kept anonymous throughout the study.

\section{Statistical analysis}

Statistical analysis was done by using SPSS version 21.0. Demographic variables will be analyzed in terms of mean + standard deviation for age and qualitative variables like age were shown in terms of frequency and percentage. The mortality rate of patients will be calculated through frequency and risk factors for AKI calculated by paired sample t-test. Statistical significance was determined at $\mathrm{P}<0.05$.

\section{Results}

\section{Baseline characteristics}

In our hospital during the given time interval, we received 334 COVID19 positive cases admitted, out of which 41 patients suffered acute kidney injury and they required hemodialysis as treatment. In contrast to COVID19 positive patients, non-COVID patients had $7.5 \%$ incidence of AKI. The frequency of acute kidney injury requiring hemodialysis in our tertiary care setup was found to be $12.2 \%(n=41)$. Amongst these there were $53.7 \%$ males $(n=22)$ and $46.3 \%$ females $(n=19)$ and the mean age of patients was found to be $64.82+11.2$ years. The mean level of lymphocyte count was found to be $11.3+4.8 \quad 10^{9} / \mathrm{L}$.

\begin{tabular}{|c|c|c|}
\hline Gender & Frequency (n) & Percentage (\%) \\
\hline Male & 22 & 53.7 \\
\hline Female & 19 & 46.3 \\
\hline
\end{tabular}

Table 1: Gender Distribution of Patients

Comorbidities of patients were also noted upon admission and they are described in table- 2 as under. The most prevalent co-morbid in these patients was found to be hypertension found in $63.4 \%$ of patients followed by diabetes in $36.6 \%$ of individuals.

\begin{tabular}{|c|c|c|}
\hline Comorbid disease & Frequency (n) & Percentage (\%) \\
\hline Diabetes & 15 & 36.6 \\
\hline Hypertension & 26 & 63.4 \\
\hline Copd & 4 & 9.8 \\
\hline Ischemic heart disease & 9 & 22 \\
\hline
\end{tabular}

Table 2: Comorbidities in the Study Group

The presenting symptoms of these patients at the time of admission were fever $(85.4 \%)$, shortness of breath and cough (73.2\%) and diarrhea (12.2\%). The mean creatinine level of patients having acute kidney injury was found to be $4.84+2.70 \mathrm{mg} / \mathrm{dl}$. Table-3 shows the laboratory parameters of the patients. During the hospital stay each patient required on average two to three hemodialysis sessions. The average duration of hospital stay for these patients was 7 days.

\begin{tabular}{|l|l|l|}
\hline Investigation & MEAN + S.D & Normal Range \\
& & \\
\hline
\end{tabular}




\begin{tabular}{|c|c|c|}
\hline Creatinine & $4.84+2.70 \mathrm{mg} / \mathrm{dl}$ & $0.1-1.2 \mathrm{mg} / \mathrm{dl}$ \\
\hline Ferritin & $1966+2675 \mathrm{mcg} / \mathrm{dl}$ & $11-300 \mathrm{mcg} / \mathrm{dl}$ \\
\hline Procalcitonin & $18+46.6 \mathrm{ng} / \mathrm{ml}$ & $<0.05 \mathrm{ng} / \mathrm{ml}$ \\
\hline Crp & $174+365 \mathrm{mg} / \mathrm{dl}$ & $<0.3 \mathrm{mg} / \mathrm{dl}$ \\
\hline D dimer & $6671+6231$ & $<0.50($ considered negative $)$ \\
\hline
\end{tabular}

Table 3: Laboratory Parameters of Patients

The in hospital mortality of COVID-19 positive patients having AKI was documented to be $73.2 \%(n=30)$ as shown in table-4. In the non-COVID positive patients the mortality rate due to AKI in our setup was found to be $4.3 \%$. The mortality rate in COVID-19 positive patients with AKI is 17 times higher as compared to the non -control group. During treatment $51.2 \%(\mathrm{n}=21)$ patients required only one hemodialysis session while others required more than one. There were 11 COVID-19 positive patients who recovered from acute kidney injury after hemodialysis sessions and were discharged from the hospital. Paired sample t-test shows that presence of hypertension as a co-morbid has higher chances of mortality due to AKI ( $\mathrm{p}$-value $=0.001$ ) whereas diabetes, COPD and ischemic heart disease have no association with mortality and AKI in COVID-19 positive patients.

\begin{tabular}{|c|c|c|}
\hline Outcome & Frequency (n) & Percentage (\%) \\
\hline Alive & 11 & 26.8 \\
\hline Dead & 30 & 73.2 \\
\hline
\end{tabular}

Table 4: Patient Outcome after Acute Kidney Injury

\section{Discussion}

The severity of COVID-19 infection and acute kidney injury are directly proportional to each other as shown in previous studies and meta-analysis. In a recent meta-analysis, It was found that patients critically ill with COVID-19 infectionHave around 76\% chances of getting acute kidney injury. The risk of a Acute kidney injury in moderate and severe COVID19 patients varied from $1.3 \%$ to $2.8 \%$ [12]. Risk factors for development of AKI include hypertension, diabetes, older age, severe respiratory failue the need for vasopressors and longer hospital stay. Some populations are at higher risk of getting acute kidney injury than others due to the risk factors and genetic variability [13]. AKI associated mortality risk showed that patients with a key I had 13 times more chances of dying as compared to the patients not having acute kidney injury. Multivariate Meta regression analysis also did not reveal any link between hypertension diabetes cardiovascular disease chronic pulmonary diseases to development of acute kidney injury Among the COVID-19 patients [14]. In our study the incidence of acute kidney injury in hospitalized COVID19 patients was found to be $12.2 \%$ whereas in other studies it ranges from $3 \%$ to $13 \%$ [15]. The variability of COVID-19 severity can be explained by ACE2 receptor gene expression among different races, as this receptor is used by SARS CoV2 to enter the target cells. ACE2 Receptor is found mostly in the kidneys, lungs and peripheral blood [16]. Cytokine storm in severe COVID-19 cases causes respiratory failure and uh its prothrombotic effects reduce perfusion to vital organs like heart and kidney. It is also observed that respiratory failure and mechanical ventilation occur simultaneously with acute kidney injury [17]. Early findings of acute kidney injury were found on urinalysis having +2 proteinuria and >5 RBCS per high power field. Kidney biopsy from visions showed a tubular lesions and severe acute tubular necrosis with prominent expression of ACE2 in tubular cells. Cytokine storm leading to immuno thrombosis, macrophage activation leads to raised ferritin $\mathrm{C}$ reactive protein and $\mathrm{D}$ dimer levels, all of these variables are also raised in our study group indicating worse clinical outcomes [18]. The in hospital mortality of patients in ICU with COVID-19 infection was found to be $50 \%$ in a recent study, In contrast in our study the mortality was found to be $73.2 \%$. In a research focusing on acute kidney injury and severe COVID-19 patients the requirement for haemodialysis was indicated in $23 \%$ of the patients and their mortality varied from 90 to $100 \%$. As our study focused on patients requiring hemodialysis as the treatment the mortality in our study group was found to be $72.3 \%$ [19].
Although COVID-19 is a respiratory virus it can damage the kidneys by various mechanisms especially in critically ill patients.

\section{Conclusion}

Since COVID-19 infection became pandemic in 2020 there still needs to be a lot of research done in different populations. Hospitalized patients with COVID-19 infection should be Screen for kidney impairment and provided proper treatment. There has been found a very close association between the severity of acute kidney injury and mortality among the critically ill patients.

\section{References}

1. Ilyas N, Azuine RE, Tamiz A. (2020). COVID-19 pandemic in Pakistan. International Journal of Translational Medical Research and Public Health. 4(1):37-49.

2. Noreen N, Dil S, Niazi S, Naveed I, Khan N, Khan F, Tabbasum S, Kumar D. (2020). COVID 19 pandemic \& Pakistan; limitations and gaps. Global Biosecurity. 1(4).

3. World Health Organization. Critical preparedness, readiness and response actions for COVID-19 [Internet]. 2020.

4. Chu KH, Tsang WK, Tang CS, Lam MF, Lai FM, To KF, et al. (2005). Acute renal impairment in coronavirus-associated severe acute respiratory syndrome. Kidney Int. 67(2):698-705. Epub 2005 Jan 28. pmid:15673319; PubMed Central PMCID: PMC7112337.

5. Yang X, et al. (2020). Clinical course and outcomes of critically ill patients with SARS-CoV-2 pneumonia in Wuhan, China: a singlecentered, retrospective, observational study. The Lancet Respiratory Medicine.

6. Huang C, et al. (2020). Clinical features of patients infected with 2019 novel coronavirus in Wuhan, China. The Lancet. 395:497-506.

7. Wu Z. \& McGoogan J.M. (2020). Characteristics of and Important Lessons from the Coronavirus Disease 2019 (COVID-19) Outbreak in China: Summary of a Report of 72 314 Cases from the Chinese Center for Disease Control and Prevention. JAMA.

8. Chu K.H, et al. (2005). Acute renal impairment in coronavirusassociated severe acute respiratory syndrome. Kidney International. 67:698- 705. 
9. Xu S, Fu L, Fei J, Xiang HX, Xiang Y, Tan ZX, Li MD, Liu FF, Li Y, Han MF, Li XY. (2020). Acute kidney injury at early stage as a negative prognostic indicator of patients with COVID-19: a hospital-based retrospective analysis. medRxiv.

10. Alkindi F, Boobes Y, Chandrasekhar Nair S, Hashmey R. (2020). SAT-028 acute kidney injury associated with Middle East respiratory syndrome coronavirus (MERS-CoV) infection. Kidney Int. Rep. 5:13.

11. Mehta R.L, Kellum J.A, Shah S.V, Molitoris B.A, Ronco C, Warnock D.G, Levin A. (2007). Acute Kidney Injury Network: Report of an initiative to improve outcomes in acute kidney injury. Crit. Care. 11:31.

12. Yang X, Jin Y, Li R, et al. (2020). Prevalence and impact of acute renal impairment on COVID-19: a systematic review and meta-analysis. Crit Care. 24:356.

13. Richardson S, Hirsch JS, Narasimhan M, et al. (2020). Presenting characteristics, comorbidities, and outcomes among 5700 patients hospitalized with COVID-19 in the new York City area. JAMA. 323:2052-2059.

14. Oliveira CB, Lima CA, Vajgel G, Coelho AV, Sandrin-Garcia P. (2020). High burden of acute kidney injury in COVID-19 pandemic: systematic review and meta-analysis. Journal of Clinical Pathology.

15. Ng JJ, Luo Y, Phua K, et al. (2020). Acute kidney injury in hospitalized patients with coronavirus disease 2019 (COVID19): a meta-analysis. J Infect. 81:647-679.

16. Walls AC, Park Y-J, Tortorici MA, et al. (2020). Structure, function, and antigenicity of the SARS-CoV-2 spike glycoprotein. Cell. 181:281-292.

17. Hirsch JS, Ng JH, Ross DW, et al. (2020). Acute kidney injury in patients hospitalized with COVID-19. Kidney Int. 98:209218.

18. Henry BM, de Oliveira MHS, Benoit S, et al. (2019). Hematologic, biochemical and immunebiomarker abnormalities associated with severe illness and mortality in coronavirus disease (COVID-19): a meta-analysis. Clin Chem Lab Med.

19. Mohamed MM, Lukitsch I, Torres-Ortiz AE, Walker JB, Varghese V, Hernandez-Arroyo CF, Alqudsi M, LeDoux JR, Velez JC. (2020). Acute kidney injury associated with coronavirus disease 2019 in urban New Orleans. Kidney360. 58:1021-1028.
This work is licensed under Creative Commons Attribution 4.0 License

To Submit Your Article Click Here: Submit Manuscript

DOI: $10.31579 / 2690-4861 / 181$
Ready to submit your research? Choose Auctores and benefit from:

$>$ fast, convenient online submission

$>$ rigorous peer review by experienced research in your field

$>$ rapid publication on acceptance

$>$ authors retain copyrights

$>$ unique DOI for all articles

$>$ immediate, unrestricted online access

At Auctores, research is always in progress.

Learn more https://auctoresonline.org/journals/international-journal-of-clinicalcase-reports-and-reviews 